\title{
Mulheres em movimento: notas sobre saberes feministas dissidentes no Sertão do Pajeú pernambucano
}

SANTANA, Paula ${ }^{1}$

\section{Resumo}

O objetivo deste ensaio é (des)alinhar notas que extrapolam a ideia de práticas pedagógicas feministas das ações coletivas do Sertão do Pajeú Pernambucano. Procura-se trazer à baila uma reflexão dialógica sobre os saberes feministas dissidentes elaborados por esses grupos a partir de suas próprias questões e desafios. Os apontamentos trazidos percorrem cenários, fontes e elaborações de uma crítica possível dos processos de interlocução entre a universidade e as ações coletivas. Assim, abre-se vereda para pensar sobre as dissidências dos saberes feministas, por meio da escuta e aprendizagem com as proposições desses coletivos.

Saberes Feministas Dissidentes. Outras Epistemologias. Ações Coletivas Feministas.

Women on the move: notes on dissident feminist knowledge in the microregion of Sertão do Pajeú, Pernambuco

\section{Abstract}

The objective of this essay is to (mis)align notes that extrapolate the idea of feminist pedagogical practices from the collective actions in Pernambuco's Sertão do Pajeú. The goal is to bring into the conversation a dialogical reflection about the dissident feminist knowledge elaborated by these groups from their own questions and challenges. The resulting prompts course through scenarios, sources, and developments of a possible critique on the processes of interlocution between the university and the collective actions. Thus, a path is open for the thinking about the dissidence in the feminist knowledge, through listening and learning from the propositions of these collectives.

Dissident Feminist Knowledge. Other Epistemologies. Feminist Collective Actions.

\section{Introdução}

Mulheres não são uma categoria social única, homogênea e monolítica. O termo "mulher" não dá conta de contemplar as representações das diversidades dos indivíduos; como diria Butler (2003, p. 20), "se alguém 'é' uma mulher, isso certamente não é tudo o que esse alguém é". É em meio a esse emaranhado de representações, imaginários e incidências do social que este

\footnotetext{
1 Doutora em Sociologia e graduada em Ciências Sociais pela Universidade Federal de Pernambuco (UFPE). Professora e pesquisadora adjunta da Universidade Federal Rural de Pernambuco - Unidade Acadêmica de Serra Talhada (UFRPE-UAST). Pesquisadora do Instituto de Estudos de África da Universidade Federal de Pernambuco. Coordenadora do Grupo de Estudos e Pesquisas Macondo: artes, culturas contemporâneas e outras epistemologias. Discute artes, outras epistemologias e suas interlocuções com gênero/sexualidade, raça/etnicidade e classe social. E-mail: paulamssantana@gmail.com
} 
ensaio se tece. A ideia é aproveitar o movimento complexo e desviante de ir e vir para lançar algumas questões ao mundo.

O espaço-vida em questão são os sertões do Nordeste brasileiro, tão recorrentes na literatura, no cinema, na música e na fotografia. O "sertão"2 do imaginário vigente, inclusive nas capitais nordestinas, é aquele submetido às forças da natureza. Seca, penúria e morte definem as narrativas emanadas aos quatro cantos sobre a região. A natureza é poderosa, mas não definidora dos sertões. É preciso compreender, à luz da imaginação sociológica, sua heterogeneidade, pluralidade e diversidade. Muito além das intempéries do clima e do tempo e das características do bioma caatinga, as profundas desigualdades regionais se agudizam pela carência de políticas de desenvolvimento sustentável para o semiárido. É preciso vontade política para lutar contra a exclusão social e fomentar alternativas econômicas locais não só para o campo, mas também para as cidades sertanejas.

As contradições do contexto social local terminam por reverberar, também, nos imaginários sobre as relações de gênero na região. É importante reconhecer que os contextos socioculturais dos sertões ainda carregam as marcas de uma ordem de gênero patriarcal: sociedades (pre)dominadas por homens na política, no mundo do trabalho e na vida privada, o que implica no cultivo de relações assimétricas e hierárquicas entre os gêneros. Mesmo diante das transformações desencadeadas pelos processos de mudança social iminentes - notadamente o crescimento das cidades, a construção de instituições públicas de Ensino Superior e pesquisa, a complexificação das relações de trabalho e o acesso à informação em rede -, ainda assim são destinadas às mulheres a primazia das atividades reconhecidas como domésticas e a situação de dependência, ao mesmo tempo em que a maioria dos homens se mantém no seu papel tradicional de provedor e chefe da família. Mantêm-se, desta maneira, valores hegemônicos patriarcais que obstaculizam, quando não impedem, a soberania e independência das mulheres. Diante disto, em sua grande parte, as mulheres sertanejas (e as brasileiras, de uma maneira geral) continuam a viver situações cotidianas de subalternidade e pouco se beneficiam, desconhecendo, até mesmo, os direitos conquistados ao longo da história.

Ser mulher no "sertão", no imaginário disseminado, representa submissão ao ambiente da casa e subordinação às lógicas de dominação masculina. Esses são retratos propagados e, na maioria das vezes, aceitos como representação cultural desse contexto. Todavia, configuram-se ambivalências nesta dinâmica, uma vez que as imagens da mulher sertaneja se contrapõem: submissão, de um lado; coragem e resistência, de outro.

Esta representação da mulher forte e que luta por seus direitos ganha fôlego nos anos 1980, quando muitas mulheres das zonas rurais começaram a

2 Aqui enfatizo o termo no singular para remeter ao uso do termo no imaginário social. Endosso que compreendo os sertões em sua diversidade e amplitude, por isso, sempre plural. 
integrar frentes de trabalho contra a seca, as ligas camponesas e os sindicatos de trabalhadores rurais. Nos sertões de Pernambuco não foi diferente. A partir de 1982, na cidade de Salgueiro, Sertão Central, as agricultoras familiares foram conjugando os seus interesses, afinando os discursos e criando conexões, trocas e vínculos entre elas próprias e com outros atores e atrizes sociais. Nos últimos vinte anos de organização do Movimento de Mulheres Trabalhadoras Rurais (MMTR) do Sertão Central de Pernambuco ${ }^{3}$, muitas ações e lutas foram desenvolvidas (MMTR, 2006). As mulheres passaram a se posicionar como trabalhadoras rurais e a exigir a participação nas decisões que afetam suas vidas, tanto na esfera pública quanto na privada.

É em meio a essas dinâmicas que as ações coletivas de mulheres sertanejas na contemporaneidade, aportadas em estudos e pesquisas que tratam dessas realidades, sinalizam que, mesmo diante de todas as conquistas dos últimos trinta anos, os direitos fundamentais não foram suficientes para trazer melhorias significativas nas condições de vida e trabalho dessas mulheres. A Constituição e a ideia de democracia participativa partem do pressuposto de um sujeito universal para a garantia de direitos; neste sentido, é preciso atentar às reinvindicações por diferença. As epistemologias e os movimentos feministas surgidos na Europa e nos Estados Unidos décadas antes também não dão conta das especificidades, demandas e necessidades de mulheres situadas em contextos periféricos. É importante reforçar que estas mulheres são interseccionadas por uma gama de outros marcadores sociais. Compreender como as mulheres, em toda a sua diversidade, lutam por direitos e resistem à cultura machista em contextos sociais diversos, é fundamental não somente para a compreensão sobre suas ações coletivas, mas também para descolonizar os estudos feministas.

Em Santana (2017) há um esforço de problematizar como os saberes científicos tout court abafaram uma gama de vozes não-hegemônicas. Neste cenário, o local é visto como limitado, monolítico, cristalizado e circunscrito. A velha dicotomia saber tradicional versus saber moderno parece se reproduzir agora nos termos local e universal. Essas dicotomias não são eficazes. Assim, - local não necessariamente traz ideias contrárias ao universal ou ao hegemônico. Os saberes locais podem contribuir com a dominação hegemônica, ou então representar obstáculos a elas. Spivak (2012) aponta a "violência

3 É importante frisar aqui a importância do nome de Vanete Almeida, uma das fundadoras do MMTR. Ativista política das lutas das mulheres rurais nas esferas local, regional e transnacional, ela se reconhecia como mulher negra e sertaneja. Percorreu todo o Sertão do Pajeú com seu ativismo. A sua atuação política iniciou-se na década de 1970, na Equipe de Educação Política da Diocese de Afogados da Ingazeira - PE, que, naquela época, desenvolvia projetos com agricultores/as. Posteriormente, foi convidada para trabalhar na Federação dos Trabalhadores Rurais de Pernambuco (FETAPE), onde teve atuação importante nos principais conflitos agrários na região. Um dos focos principais de sua mobilização política diz respeito à organização política das trabalhadoras rurais. Valdete Almeida colaborou, ainda, com a fundação do Movimento de Mulheres Trabalhadoras Rurais do Nordeste (MMTR-NE) e da Rede de Mulheres Rurais da América Latina e do Caribe (REDELAC). 
epistêmica" que a ciência submeteu às formas de conhecimento gestados fora de seus cânones e, por conseguinte, aos sujeitos produtores desses saberes. 0 que há é uma gama diversa de subalternos, desprovidos de uma consciência autêntica pré ou pós-colonial, munidos de "subjetividades precárias" construídas no marco da "violência epistêmica" colonial. E entre essas "camadas subalternas", as mulheres, na concepção de Spivak, estariam ainda mais aquém de uma gramática própria para construir suas falas.

Na senda de um esforço heurístico para descolonizar a academia, assumo que a minha existência como "mulher - intelectual - não branca - periférica", que constrói saberes a partir de uma instituição pública de Ensino Superior no Sertão de Pernambuco (Nordeste e interior do Brasil), compõe, por si só, algumas das intersecções diversas que desafiam as epistemologias feministas à compreensão do mundo em suas várias facetas. Todavia, é preciso ir mais adiante. Para tanto, trago ao debate, de forma ensaística, ações coletivas de mais mulheres diversas do Sertão do Pajeú pernambucano, bem como as contribuições de autoras não brancas ${ }^{4}$ e não ocidentais para as discussões sobre gênero, feminismos e educação, no afã de adentrar em outros territórios de educação que se inscrevam na práxis do que reconhecemos como sendo saberes dissidentes, pelo enfrentamento teórico, metodológico, ético e epistemológico que travam junto aos saberes e padrões hegemônicos.

No início dos anos 1990, Haraway (1995) já mostrava que as feministas de países periféricos vinham reivindicando teorias próprias, criticando os universalismos e tecendo elaborações sobre o potencial explicativo do conceito de gênero, uma vez que outras forças se combinavam para constituir o lugar não só das mulheres, mas dos subalternos. Aquele feminismo vindo do centro, registra Ella Shohat (Maluf; Costa, 2001), tendeu a transpor categorias de análises tais como patriarcado e homofobia para cenários não europeus, como se estas existissem ou houvessem existido em todos os lugares e em todos os tempos, operando sobre os mesmos referentes. Esta forma deslocada de lidar com certas categorias ocidentais e seus binarismos estruturantes foi apontada como (trans)histórica e (trans)geográfica, o que, mesmo sem intenção clara, acabava por resultar na reprodução do discurso orientalista, machista, racista e colonialista da ciência canônica. Tem-se aqui ideias foras do lugar.

Feministas com diferentes formações buscam por novas estratégias epistemológicas. Nomes como Chela Sandoval (1991), bell hooks (2013), Audre Lorde (2009), Norma Alarcón (1990), Cherríe Moraga \& Glória Anzaldúa (1983) sobressaem neste momento de inflexão. O sujeito centrado do conhecimento iluminista - homem, branco, europeu, heterossexual e cristão - era, então, posto

4 É importante reiterar que neste ensaio há uma profusão de vozes em diálogo e que autoras advindas de contextos mundiais centrais também têm espaço; contudo, há um esforço em prol da coerência metodológica (e ideológica) de trazer mais enfaticamente autoras de contextos periféricos. 
em xeque pelas formulações que reivindicam um lugar de fala e ressaltam a importância político-epistemológica de um "saber localizado" e dissidente.

Nesse sentido é que vêm sendo desenvolvidas não apenas técnicas, dinâmicas e práticas educativas diversas que visam sensibilizar mulheres (e homens, também) para as questões de gênero, mas, sobretudo, novos territórios de educação em que os movimentos sociais, os coletivos e a academia buscam compreender as dinâmicas nas quais se inserem. Essas práticas políticopedagógicas, aqui denominadas de "pedagogias feministas", voltam-se para uma educação libertadora, e têm sido empregadas no trabalho com setores populares, na esfera da educação formal e na formação interna dos grupos.

Notadamente, as pedagogias feministas têm sido bastante teorizadas, aplicadas e avaliadas em diferentes frentes, incluindo-se aí os estudos sobre mulheres, comunicação, educação e estudos culturais, dentre outros (WALLER, 2005, p.19), já existindo, hoje, uma ampla bibliografia ${ }^{5}$ sobre práticas pedagógicas feministas também no Ensino Superior.

Entretanto, essas teorizações, por vezes, não conseguem abarcar a complexidade e o desafio de ser mulher em contextos localizados, terminando por reproduzir assimetrias sociais e violências epistêmicas. As dinâmicas que ganham forma no Sertão do Pajeú, hoje, endossam a necessidade de se agudizar a mirada. Como já fora discutido aqui, o Movimento de Mulheres Trabalhadoras Rurais trouxe demandas antes invisibilizadas em várias frentes, a saber: no movimento de trabalhadores rurais, na academia e no movimento feminista. Hoje, passados mais de trinta anos desde a sua formação, as mulheres da região apresentam outros desafios às mesmas esferas. Várias dessas jovens mulheres que ensejam os coletivos feministas da região têm uma

5 Ver ALONSO, Graciela Beatriz; DìAZ, Raúl (orgs.) (2002). Hacia una pedagogía de las experiencias de las mujeres. Buenos Ayres: Miño y Dávila, 2002; CELIBERTI, Lilian (1997), "Reflexiones acerca de la perspectiva de género en las experiencias de educación no formal con mujeres". In: T. Buttner, I. Jung e L. King (orgs.) Hacia una pedagogía de género: experiencias y conceptos innovativas ponencias y documentos del Seminario Latinoamericano sobre Experiencias en Educacíon No Formal con Mujeres realizado en Melgar, Colombia, del 28 de octubre al 1 de noviembre de 1996. Fundación Alemana para el Desarrollo Internacional (DSE), Centro de Educación, Ciencia y Documentación (ZED), IUE, CAFAM - 1997; CRESPO, Mónica (1997). "Capacitar en género: un desafío personal". In: Susan Paulson y Mónica Crespo (eds.), Teorías y prácticas de género: una conversación dialéctica. Bolivia: Embajada Real de los Países Bajos; HOOKS, bell (1994). Teaching to Transgress: education as the practice of freedom. New York: Routledge; HOOKS, bell (1989). Talking Back: thinking feminist, thinking Black Sheba, London; PORTELLA, Ana Paula; GOUVEIA, Taciana (1998). Ideias e dinâmicas para trabalhar com gênero. Recife: SOS CORPO; WEILER, K. (1991) "Freire and a feminist pedagogy of difference." Harvard Educational Review, 61 (4), 449-474; WILLIAMS, Suzanne et alli, (1999). Manual de formação em gênero da Oxfam. Recife: SOS Corpo, Gênero e Cidadania: OXFAM, 1999; ZUÑIGA, Miryan E. (1997). "Apuntes para una pedagogia de los programas educativos com mujeres de sectores populares". In: T. Buttner, I. Jung e L. King (eds), (orgs.) Hacia una pedagogía de género: experiencias y conceptos innovativas. ponencias y documentos del Seminario Latinoamericano sobre Experiencias en Educacíon No Formal con Mujeres realizado en Melgar, Colombia, del 28 de octubre al 1 de noviembre de 1996. Fundación Alemana para el Desarrollo Internacional (DSE), Centro de Educación, Ciencia y Documentación (ZED), IUE, CAFAM. 
experiência muito distinta de suas antecessoras do Movimento de Mulheres Trabalhadoras Rurais. A maioria nasceu e cresceu na zona urbana, são solteiras, não possuem filhos, reconhecem-se como mulheres negras e LGBTQI ${ }^{6}$, vêm de famílias da classe trabalhadora da cidade e têm formação superior. Por isso, terminam construindo outras estratégias de luta e formação. Por meio de suas inserções na universidade, alguns coletivos nasceram. Os diálogos travados com a academia são recorrentes. Diante deste cenário, é importante perguntar: como estes grupos dialogam e ressignificam suas experiências educativas com uma instituição que foi tão violentadora de seus saberes e existências, mantendo-se, por muito tempo, distante dos movimentos sociais?

Para tanto, é preciso (des)alinhar notas que extrapolem a ideia de práticas pedagógicas feministas das ações coletivas do Sertão do Pajeú pernambucano. A partir de suas próprias elaborações, almeja-se construir uma reflexão dialógica sobre os saberes dissidentes feministas elaborados por esses grupos a partir de suas próprias questões e desafios. Os apontamentos a seguir percorrem cenários, fontes e recursos de uma crítica possível desses processos. Uma crítica que está sendo levada a cabo a partir de diferentes articulações coletivas que confluem, aqui, num diálogo em comum.

A partir da construção do Grupo de Estudos e Pesquisas Macondo: artes, culturas contemporâneas e outras epistemologias na Universidade Federal Rural de Pernambuco - Unidade Acadêmica de Serra Talhada (UFRPE-UAST), em 2015, iniciou-se um longo processo de compilação de textos que tangenciassem a perspectiva decolonial, mas que, sobretudo, evidenciassem práticas intelectuais dissidentes, articuladoras de uma práxis de intervenção no contexto social. A ideia era travar uma familiarização com categorias emergentes de análise crítica, mas também tomar contato com a(r)tivismos decolonizantes. Desta forma, as intervenções aqui reunidas são a expressão de projetos políticos em rede que englobam o Macondo, a universidade e outros coletivos que se atualizam e dialogam através de vários espaços sociais, diluindo fronteiras problemáticas como a oposição "a academia" e "a sociedade".

A partir de um diálogo que vem sendo alimentado desde o surgimento do Macondo com dois exemplos de ações coletivas recentes do Sertão do Pajeú, abre-se vereda para pensar sobre as dissidências dos saberes e práticas feministas, por meio da escuta e aprendizagem com as proposições desses coletivos. Dissidência não se refere apenas a polarizações entre "dentro" e "fora", "superfície" e "profundeza". Também não diz respeito a um distanciamento sem retorno. Muito menos à incomunicabilidade. Pelo contrário, dissidência, na perspectiva aqui ensejada, é um movimento constante de ir e vir. Aproximar e tomar distância. Política, teoria e instituições interagem em dissidência, realçando e descortinando, em momentos distintos, os contornos e as proteções

6 Sigla para Lésbicas, Gays, Bissexuais, Transgêneros, Travestis, Transsexuais, Queer e Intersexo. 
que sustentam determinadas ortodoxias, ao passo que conformam, também, heterodoxias, indisciplinas e insubmissões.

Assim, vamos ao encontro do Coletivo $\mathrm{FUÁH}^{7}$, que, segundo Manu Silva ${ }^{8}$, nasceu em 2015, com a criação de um grupo de WhatsApp ${ }^{9}$ para ajudar uma estudante serra-talhadense a superar as dificuldades do processo de transição do cabelo alisado para o cabelo afro. Em meio às conversas sobre negritude, desabafos sobre experiências de injúria racial e agressões contra a mulher, as jovens negras feministas, a maioria advinda do meio acadêmico, estudantes de diversos cursos de graduação da UFRPE-UAST, instigaram-se para 0 enfrentamento do machismo e racismo com base nos momentos de discriminação sofridos por elas.

Para isso, organizaram, já em novembro de 2015, o I Encontro de Cresp@s e Cachead@s de Serra Talhada, evento que reúne várias mulheres negras da região para discutir a afirmação da identidade negra. Em 10 de abril de 2016 iniciaram-se, efetivamente, as articulações como movimento social e a reflexão sobre questões sociais mais abrangentes do movimento negro, para além da estética e da cultura. Hoje, o grupo conta com cerca de cinquenta participantes; destas, oito são responsáveis por coordenar as ações. Segundo Manu Silva (2018):

Começamos a nos apropriar das linhas de pensamento do Feminismo Negro para pautar intervenções em escolas, universidades e na interação outros movimentos. A principal bandeira do Coletivo FUÁH está fundamentada na tríade dos movimentos sociais brasileiros que pensam fundamentalmente gênero/raça/classe em suas pautas, cabendo também a articulação com movimentos sociais da cidade e da região que pensam a sexualidade e atuam em prol das pautas dos movimentos de direitos humanos (informação verbal).

É interessante observar como as práticas pedagógicas feministas têm força no coletivo. O principal objetivo do grupo é reunir mulheres negras - vale lembrar que há uma abertura para homens negros também - para mover estruturas sociais a partir da educação, dialogando com a sociedade serratalhadense, as instituições educacionais e outros movimentos sociais. Essa

"[...] o nome FUÁH é um levante contra a conotação negativa à palavra associada aos cabelos cacheados e crespos. Pensamos por bem usar o termo FUÁH como revolução, proposta de desconstrução do racismo, de estereótipos e preconceitos da nossa sociedade, a partir da ideia de sororidade entre as Fuáhs" (Blog COLETIVO FUÁH, 2016).

8 Feminista negra e militante dos direitos LGBTQI. Além do ativismo nos coletivos FUÁH e Diverso, Manu Silva é graduada em Licenciatura em Letras pela UFRPE-UAST.

9 Aplicativo de comunicação instantânea usado em telefones celulares. 
triangulação aponta para rumos pertinentes diante dos interesses do coletivo, pois abre espaço para uma pedagogia antirracista e antipatriarcal.

Segundo a militante, as atividades de formação não são propostas ainda pelo Coletivo FUÁH, mas há um empenho para participar ativamente de espaços de diálogo e construção de conhecimento aventados por outras instituições, a exemplo das faculdades da Autarquia Educacional de Serra Talhada ${ }^{10}$, da Faculdade Integrada do Sertão (FIS) e da Universidade Federal Rural de Pernambuco - Unidade Acadêmica de Serra Talhada (UFRPE-UAST); além disso, palestras, encontros e formações propostos pelas secretarias da Prefeitura Municipal de Serra Talhada, especialmente a Coordenadoria da Mulher e de Promoção à Igualdade Racial.

Os debates sobre os Feminismos nunca cessam e sempre demandam novas posturas e abordagens em nossa atuação. Abrangemos principalmente em temas relacionados à segurança, preconceito racial e machismo, cultura, educação e mercado de trabalho. Há uma necessidade maior do coletivo em oportunizar espaços de debate sobre religiosidade, ancestralidade, saúde e direitos da população negra. Assim como também as questões do próprio Feminismo Negro, que difere dos demais que passeiam entre as mulheres que compõem o coletivo (SILVA, 2018) (informação verbal).

As ativistas do coletivo estão atentas ao estado da arte das discussões sobre desigualdades e interseccionalidades, tornando a formação interna do grupo sólida e constante. Os diálogos travados entre cada uma delas, advindas de lugares de fala distintos, possibilita uma reflexão e crítica constante sobre esses saberes disciplinares e canônicos a que têm acesso. Para Manu Silva, elementos fundamentais para a formação feminista do grupo foram blogueiras, digital influencers e professoras da universidade. Em alguns casos, "manas" se tornaram formadoras de opinião, como a estilista Dani Santos, que tem sua própria marca de roupas e usa como modelos em seus desfiles mulheres negras, gordas, que estão à margem do padrão de beleza do mercado da moda. Assim como mulheres influentes no mundo inteiro, desde escritoras como Chimamanda Adiche, Djamila Ribeiro, Sueli Carneiro, Conceição Evaristo, beel hooks, Mel Duarte, entre outras, a militantes e cantoras como Jéssica Caitano, Gabi da Pele Preta, Preta Rara, Tássia Reis, Yzalú, Linn da Quebrada etc. Nessa mesma senda, as redes sociais são grandes aliadas não só para o aprendizado do coletivo, mas também para a difusão de suas bandeiras. O WhatsApp, a fanpage no Facebook e o Instagram são tentativas de aproximar e difundir as pautas do

10 Formada pelas seguintes faculdades: Faculdade de Formação de Professores de Serra Talhada (FAFOPST), Faculdade de Ciências da Saúde de Serra Talhada (FACISST) e Faculdade de Ciências Humanas e Sociais de Serra Talhada (FACHUSST). 
coletivo. Soma-se a isso a produção de vídeos, ao vivo ou gravados, para realizar campanhas e promover ideias.

Dentre as ações e parcerias com outras instituições (governamentais e não governamentais) e outros coletivos, Manu Silva destaca:

Temos relação direta com o Movimento Diverso, grupo que discute a população LGBTQI de Serra Talhada, e recentemente começamos a dialogar com a Marcha Mundial das Mulheres Pernambuco, assim como um diálogo um pouco menos avançado com a Marcha das Mulheres Negras de Pernambuco - Sertão. Na UFRPE-UAST encontramos braços a postos para lutar junto com o Grupo de Estudos e Pesquisas Macondo: artes, culturas contemporâneas e outras epistemologias; o Dadá Grupo de Pesquisa em Relações de Gênero; e o Coletivo Ebasta! Buscamos parcerias de financiamento e participação nas ações com a Secretaria de Desenvolvimento Social e Cidadania de Serra Talhada, mais precisamente com a Diretoria de Igualdade Racial e a Secretaria-Executiva da Mulher no município" (SILVA, 2018) (informação verbal).

Vale lembrar a importante colaboração e parceria do coletivo com a UFRPE-UAST. Desde o seu surgimento, o grupo tem ocupado um espaço legítimo como voz do movimento feminista negro em sala de aula e na articulação com os diretórios acadêmicos. O FUÁH participa há três semestres consecutivos de atividades integradas das disciplinas de Fundamentos Históricos, Filosóficos e Sociológicos da Educação e de Educação para as Relações Étnico-raciais, ministrando palestras, participando de rodas de diálogo e oficinas didáticas. Entretanto, segundo Manu Silva, mesmo com uma forte e longa teia de articulações institucionais, o coletivo ainda esbarra em limites por não conseguir realizar discussões e ações para povos tradicionais (de terreiro e quilombolas) e, especificamente, LGBTQI. No entanto, são pautas que transversalmente são tocadas devido às demandas pessoais de militantes do coletivo.

Manu Silva reforça o empenho do grupo para realizar palestras, mesasredondas, rodas de diálogo e "contação" de histórias voltadas para as temáticas das Relações Étnico-raciais e Gênero em diversas instituições de ensino ou de apoio às pessoas em situação de vulnerabilidade social, como o Centro de Referência de Assistência Social (CRAS) e o Centro de Referência Especializado de Assistência Social (CREAS), dentre outros. Deste projeto surgiu o trabalho acadêmico intitulado "Fazendo Fuáh: por uma educação antirracista e plural", que foi aprovado para participar da VIII Conferência Latinoamericana e Caribenha de Ciências Sociais (CLACSO). Neste momento, o grupo está à frente de uma campanha de financiamento coletivo para viabilizar a participação de algumas de suas integrantes no evento, que acontecerá na cidade de Buenos Aires, Argentina, de 19 a 23 de novembro de 2018. Segundo as militantes, no texto difundido na página do crowdfundig: 
A importância dessa viagem é imensurável, já que poderemos mostrar um pouco de nossa luta contra a desigualdade racial para mulheres de diversos lugares do mundo, trocar experiências e adquirir conhecimento e força para continuar travando esta batalha contra o racismo institucional que ainda prejudica muitas crianças negras dentro e fora dos educandários dos Sertões (SILVA, 2018) (informação verbal).

Vê-se, assim, como as interlocuções entre ação coletiva e academia estão entremeadas. Na pesquisa, o coletivo problematiza que suas práticas pedagógicas antirracista e feminista são caminhos para uma educação plural e usam o espaço de um congresso acadêmico para dar relevo à crítica, ao passo que aprovar um trabalho de pesquisa em um congresso internacional também é uma instância importante para referendar o ativismo do grupo na cidade. Essa tensão é inerente aos saberes feministas dissidentes.

Neste contexto, Manu Silva lembra que:

A cultura local não interfere na atuação do Coletivo FUÁH, mas nos dão motes importantes para debater, pois se trata de um coletivo feminista e de maioria feminina que nasce em um cenário coronelista, patriarcal e misógino. Os índices de violência contra a mulher em Serra Talhada são preocupantes, mesmo depois da instalação de políticas e equipamentos de enfrentamento à violência de gênero. $O$ mercado de trabalho na cidade também é cruel com as mulheres e se tratando de interior, sertão pernambucano, há pouco avanço na desconstrução da cultura machista e prevalência de espaços conservadores. A cultura local nos dá assunto e motivo para militar" (SILVA, 2018) (informação verbal).

O FUÁH frequentemente ocupa o espaço público com suas ações pedagógicas feministas. Em 2015, na praça do bairro do Ipsep, majoritariamente frequentada por jovens e grupos de família, realizaram um "Turbantaço", isto é, uma oficina de turbantes para mulheres e homens. Também realizaram saraus de poesia negro-brasileira na praça da Concha Acústica, assim como o I e II Encontro de Cresp@s e Cachead@s, em 2015 e 2016, respectivamente. Houve também oficina de fanzines na praça, e várias das reuniões do coletivo ocorrem em locais públicos. Essas têm sido estratégias pedagógicas importantes para se fazer da rua um lugar seguro para as mulheres, via pela luta e resistência.

A pouco mais de sessenta quilômetros de Serra Talhada, também localizada no Sertão do Pajeú, está a cidade de Afogados da Ingazeira, onde surge o Coletivo Espaço e Resistência. É basilar frisar que ambos os coletivos 
surgem com pouco menos de um ano de diferença, a partir de uma dinâmica poderosa de emergências de ações coletivas na região. Laeiguea Bezerra ${ }^{11}$, uma das representantes do grupo, conta que o mesmo nasceu em 14 de maio de 2016, depois da formação do Coletivo Mangaio ${ }^{12}$, com o objetivo de incentivar e disseminar as produções musicais independentes:

Iniciamos com a música independente e autoral, que já é um ato político, mas é impossível não levantar outras bandeiras. Hoje somos engajadas com o LGBTQI, mulheres, negras e estamos levantando todas que estiverem preocupadas com o bem-estar de todos. (BEZERRA, 2018) (informação verbal).

É pertinente ver como as preocupações artísticas e culturais são interseccionadas pelos marcadores de gênero/sexualidade e raça/etnicidade, tecendo perspectivas feministas para as práticas do grupo. Quando perguntada sobre qual é a forma de filiação de membros do coletivo e se ele é exclusivo para mulheres, a ativista responde que não há exatamente uma filiação. As pessoas interessadas aproximam-se e se integram ao grupo de forma espontânea, e aquelas pessoas que são mais engajadas compõem uma equipe para organizar os eventos. Apesar de não haver uma preocupação em construir um coletivo majoritariamente composto por mulheres, Laeiguea Bezerra (2018) consegue perceber uma identificação forte das mulheres com o trabalho do coletivo: "Elas frequentam, algumas declamam/leem poesias no microfone (algumas se dispõem a ajudar na organização) e sempre estão lá. Elas sempre estão lá". Neste trecho, nota-se a construção coletiva de um protagonismo feminino ante as pautas do coletivo. Por esta razão, surge uma potência de garantir ações específicas voltadas para as mulheres:

"Nunca tínhamos pensado numa estratégia de aproximação a partir do gênero, apenas, inicialmente, de acordo com o gosto musical. Mas fazer, a exemplo dos outros coletivos feministas de Serra Talhada e Triunfo (com os quais dialogamos) a Balada Feminista, trouxe um feedback positivo: percebemos nas

11 "Sou Laeiguea Bezerra de Souza, milito em algumas frentes: na Educação Básica enquanto professora de Língua Portuguesa que promove reflexões sobre a língua com um viés sociopolítico; no movimento LGBT como uma das fundadoras e ativistas do Grupo Filh@s do Pajeú; na organização de eventos de circulação de músicos e artistas independentes no interior do estado de Pernambuco, com os Coletivos Espaço e Resistência e Mangaio. É mestra em Letras pela Universidade Federal Rural de Pernambuco - Unidade Acadêmica de Garanhuns e uma das organizadoras do evento Sertão Alternativo, em Afogados da Ingazeira" (BEZERRA, 2018).

12 Coletivo intermunicipal de bandas alternativas do Sertão do Pajeú. 
mulheres presentes a sensação de estarem em um lugar seguro, empoderado.

Aqui é válido avigorar o caráter pujante das interações entre os coletivos. A "Balada Feminista" é uma proposta colaborativa do Coletivo FUÁH e do Grupo de Estudos e Pesquisas Macondo (UFRPE-UAST), surgida após reiterados episódios de violência contra a mulher na Concha Acústica do município de Serra Talhada, espaço onde vários grupos juvenis se encontram aos finais de semana. A ideia era criar um espaço seguro de diálogo entre as jovens mulheres que frequentam a Concha Acústica e, após a discussão, realizar uma festa com protagonismo feminino: as DJs da noite são sempre mulheres e o repertório é todo de cantoras. Constrói-se, assim, um lugar de entretenimento apartado da resistência e do enfrentamento machista, e ainda politicamente engajado com a causa feminista. Mesmo que todos os grupos em questão sejam muito jovens (tanto no que tange à geração de suas integrantes quanto no tocante ao surgimento), a partilha das iniciativas dos coletivos aponta para uma movimentação feminista coesa e que se desdobra muito além dos municípios de emergência de cada coletivo.

Dentre as ações e parcerias do coletivo Espaço e Resistência com outras instituições/grupos (governamentais e não governamentais), aparecem várias instituições feministas e de mulheres históricas do Sertão do Pajeú, como o Fórum de Mulheres do Pajeú, Grupo Benvirá (antigo Grupo Mulher Maravilha) e - Núcleo de Estudos de Gênero (NEG) da Faculdade do Sertão do Pajeú (FASP). Vê-se um coletivo que tem como elemento motivador de sua construção o fomento de um circuito para a música alternativa em Afogados da Ingazeira, uma profunda preocupação feminista. A música, de uma maneira geral, é reprodutora das estruturas do patriarcado, tanto no conteúdo quanto na sua conformação técnica. Existe um número significativo de cantoras, mas poucas compositoras, musicistas e técnicas de som. O cenário da música alternativa, apesar de demonstrar uma maior abertura às pautas feministas, também reproduz, em alguma medida, as lógicas da desigualdade de gênero. Dentre as bandas que participam do Coletivo Mangaio e compõem o contexto musical de Afogados da Ingazeira, em específico, contam-se nos dedos as mulheres musicistas. A nossa interlocutora, Laeiguea Bezerra, é uma das poucas produtoras artísticas do Pajeú. A cultura machista que permeia a cena musical tem gerado tensões com os coletivos feministas da região, uma vez que existe pouquíssima abertura para a escuta e valorização do trabalho artístico das mulheres.

Para enfrentar essas tensões e fraturas, as atividades realizadas pelo Espaço e Resistência terminam por hibridizar várias linguagens e metodologias pedagógicas feministas: palestras, oficinas, debates, atos de rua, batucada, shows. Segundo Laeiguea Bezerra, os temas mais discutidos nessas ações 
versam sobre violência, conjuntura, produção artística, direitos das mulheres e questões LGBTQI. O coletivo traz em seu bojo elementos críticos anti-patriarcais importantes para o debate. Nota-se no grupo a configuração de práticas pedagógicas feministas afinadas com a irrupção dos feminismos latinoamericanos na contemporaneidade: as batucadas, por exemplo, ganham fôlego na Marcha Mundial das Mulheres e tornam-se um elemento metodológico relevante de ocupação do espaço público pelos corpos e mentes das ativistas. Assim como ocorre com o FUÁH, o Espaço e Resistência também realiza uma ocupação constante na cidade, na "Pracinha do Cuscuz". É lá onde ocorrem vários shows e ações do coletivo.

Em ambas articulações coletivas o conhecimento acadêmico tem papel fundamental para a emergência dos saberes dissidentes elaborados. Surge, então, um fenômeno marcado pela ambivalência, pois estamos diante de múltiplas assimetrias: de um lado, coletivos feministas, com predominância de mulheres negras e pessoas LGBTQIs em suas formações, surgimento e atuação no sertão pernambucano, porém com foco nas zonas urbanas, Nordeste do Brasil (periferia da periferia), e formado por mulheres das camadas mais pobres da sociedade, algumas, inclusive, advindas dos sítios (zona rural). Do outro lado, a universidade brasileira, nascida tardiamente no século XX em consequência do processo de colonização que deixou marcas indeléveis no país, com uma intensa relação de dependência da colônia à metrópole, e que se dirigiu para uma elite econômica e social. Ficou, assim, distante do sujeito subalterno brasileiro. Já os movimentos sociais no Brasil, do campo e dos centros urbanos, se destacam tanto no processo de luta e reivindicação de direitos quanto na formação de seus militantes. O encontro entre essas culturas distintas e distantes foi possibilitado por uma série de políticas públicas em educação que descentralizaram e interiorizaram as universidades públicas federais. As mulheres negras, LGBTQIs, sertanejas e das classes populares que estão à frente desses coletivos formaram-se neste ambiente.

Porém, o espaço acadêmico interiorizado também reproduz assimetrias coloniais e iluministas no que toca às formas de construção de conhecimento. Tanto as universidades construídas para as cidades do interior quanto os campi e unidades/centros acadêmicos de universidades centrais que foram trazidos para o interior têm em suas bases fundantes tecnologias institucionais destinadas à manutenção de certos regimes de produção, os quais se materializam tanto na estrutura burocrática dependente de universidades centrais e tradicionais como no vergalhão de seus Planos Político-Pedagógicos. Desta maneira, as condições de realização do trabalho intelectual em sua plenitude, pensadas e geridas por diferentes hegemonias institucionais, terminam por promover ativamente determinados saberes, ao passo que dificultam a viabilidade de outros tipos de saberes, inclusive suprimindo e invisibilizando-os. 
A experiência local dos Coletivos FUÁH e Espaço e Resistência aponta que a universidade, com suas estruturas de promoção das práticas cognitivas legítimas, só adquire real potência social quando se encadeia com outros atores e atrizes da sociedade civil e política, a partir da conformação de saberes dissidentes e de interesses múltiplos e mutuamente reforçados. Nesses encontros dissidentes e insubmissos são elaborados muitos problemas da contemporaneidade, assim como as soluções provisórias para eles.

Interlocuções desse tipo adquirem formas variadas e impulsionam diferentes estratégias de poder, luta e resistência. Os grupos, no entre-lugar da dissidência, tecem redes de ação coletiva entremeadas e complexas, cuja força persuasiva se nutre dos saberes construídos no meio acadêmico, sem, contudo, resignar-se a eles. Assim, o Coletivo FUÁH e o Coletivo Espaço e Resistência empenham-se para construir conhecimentos responsáveis, tanto em suas reflexões internas quanto em suas práticas pedagógicas feministas, associados a compromissos políticos evidentes. A aplicação desses critérios éticos depende da reflexão permanente sobre posicionalidades, ou seja, sobre os lugares ocupados num dado contexto e momento e sobre quais lugares não são desejáveis de ocupar. Soma-se a isso uma profunda conscientização sobre as incidências de determinantes sociais como gênero/sexualidade, raça/etnicidade e classe na vida social. Os efeitos práticos da indagação sobre esses saberes feministas dissidentes oferecem outras bases para o desenvolvimento e a enunciação dos resultados das práticas pedagógicas feministas e investigativas desses grupos, sinalizando o advento de uma "ciência sucessora" dissidente como diria Haraway (1995).

Ao desenvolver investigações, emitir relatórios, frequentar eventos científicos, escrever artigos, produzir imagens, enunciar discursos políticos em eventos diversos ou nas redes sociais, apontam-se caminhos para uma incorporação e transmutação das pedagogias feministas para além dos preceitos acadêmicos iluministas, conformando, assim, saberes feministas dissidentes. Quando o Coletivo FUÁH, por exemplo, organiza uma campanha de financiamento coletivo para participar de um evento acadêmico, trazendo ao debate uma pesquisa sobre suas práticas feministas negras, termina por questionar as hierarquias acadêmicas e disputa seus efeitos e funções. Nesse sentido, ao invés de atuar no registro da reprodução, abastecendo o aparelho disciplinar herdado, o coletivo ressignifica dinâmicas produtivas, exercendo uma reflexão crítica não apenas sobre as matrizes teóricas, formas de escrita e procedimentos de pesquisa em voga, mas também a respeito das ferramentas político-institucionais disponíveis à ação transformadora.

Diante das experiências dos coletivos em discussão, é possível ver que a fratura das cadeias de reprodução disciplinar tem mais a ver com uma forma de agir do que com um conteúdo ou uma tendência determinada de antemão. Muitas das ativistas do FUÁH e do Espaço e Resistência tiveram formação acadêmica ampla. Estudaram em universidades públicas de 
qualidade, fizeram mestrado, integraram programas de iniciação à docência e à pesquisa, trabalharam em projetos de extensão e ensino, mas, apesar de produtoras de conhecimento em um contexto institucionalizado, hierárquico, elitizado, machista, LGBTQI fóbico e racista, assumem, não somente em suas reflexões, mas também a partir de suas próprias existências, os antagonismos abrangentes que entranham (e estranham) qualquer instituição. Esse saber feminista dissidente que ganha forma em cada ação coletiva dos grupos em questão duvida dos consensos estabelecidos, pergunta-se pelo que está suprimido em cada ato performativo (desde o plano de ensino de uma disciplina na universidade até a cerimônia de abertura de um congresso), abandona a perspectiva de uma redenção acrítica pela educação hegemônica iluminista e traz à baila o ponto de vista da contradição e da diferença. Os coletivos tencionam a vida acadêmica, ao mesmo tempo em que ocupam outros espaços de realização, notadamente os contextos culturais locais e as instituições públicas responsáveis por acolher crianças e adolescentes em situação de vulnerabilidade social.

Ganha corpo por meio dessa atuação híbrida dos coletivos outras práticas de produção intelectual, de pedagogia feminista e outros territórios de educação. Esse saber feminista dissidente abre caminho para a dialogia e para o conflito. A academia e as ações coletivas são espaços fronteiriços que fazem emergir uma ecologia dos saberes dissidentes. Na intersecção e tradução entre dois mundos, produz-se epistemologias alternativas a lógicas da globalização neoliberal e aos feminismos hegemônicos, configurando-se como uma contrahegemonia dissidente. Ao mesmo tempo, demonstra-se que a academia não só é constitutiva das realidades políticas como também depende de uma série de dinâmicas sociais tão difundidas quanto questionáveis para existir tal como a conhecemos.

Aqui trago as notas derradeiras deste ensaio, que pretende servir como portas e janelas abertas para outras reflexões desdobradas. A proposta é ir ainda mais fundo na descrição densa dos saberes, dissidências, relações de poder, símbolos e tempos pedagógicos das culturas diversas, ações coletivas e pedagogias feministas. Os saberes feministas dissidentes que perpassam as duas intervenções aqui reunidas não respondem apenas ao imperativo de falar as coisas de outra forma e com outros interlocutores. Na verdade, extrapolam a ideia já sedimentada de uma "pedagogia feminista".

Os saberes feministas dissidentes abarcam um conjunto de estratégias e procedimentos que rompem com a lógica de que o conhecimento se encontra apenas naquele que é fonte de autoridade e propõe, então, a valorização das várias vozes, sendo o diálogo sua dinâmica problematizadora, no qual todas e todos são igualmente falantes e ouvintes, capazes de expressar diferentes saberes. As situações de aprendizagens são momentos privilegiados em que o conhecimento é construído colaborativamente (LOURO, 1997). 
Nesta perspectiva, essas atrizes e atores sociais passam a acreditar e a legitimar seus saberes, dando sentido às suas falas e aos seus desejos. Mulheres em movimento que elaboram e promovem alternativas políticas e epistêmicas ao mapear atentamente as manifestações contemporâneas e localizadas do saber acadêmico, abrindo senda para outros mundos possíveis por meio da desconstrução dos alicerces sedimentados desde o lluminismo e a invasão colonial. Potencializam, deste modo, vetores de transformação não só da ideia de ação coletiva, mas também de toda a aparelhagem acadêmica.

Adentrar no universo dos saberes feministas dissidentes é, portanto, reelaborar as concepções de ciência, ou seja, pensá-las a partir de sua instabilidade. Os coletivos FUÁH e Espaço e Resistência mostram que são muitos os lugares de formação, resistência e luta: as casas, as salas de aula, os auditórios, as vielas, as ruas, as praças, os pátios, os corpos. Muitas teias de linguagem e de produção de saber. Todas essas tramas são marcadas pela dissidência, impermanência e heterodoxia.

\section{Referências}

ALARCÓN, Norma. The theoretical subject(s) of this bridge called my back and angloamerican feminism. In: ANZALDÚA, Gloria (Org.). Making face, making soul = haciendo caras: creative and critical perspectives by feminists of color. San Francisco: An Aunt Foundation Book, 1990.

BEZERRA, Laeiguea. Laeiguea Bezerra: entrevista. Entrevistadora: Paula Santana. Afogados da Ingazeira-PE, mar. 2018. Entrevista concedida para elaboração do presente ensaio.

BUTLER, Judith. Problema de gênero: feminismo e subversão da identidade. Rio de janeiro: Civilização Brasileira, 2003.

COLETIVO FUÁH. Queremos fazer FUÁH contra toda forma de opressão racial/étnica, de gênero e sexual à população negra. Blog do Coletivo FUÁH, 2016. Disponível em: http://coletivofuah.blogspot.com.br/2016/05/queremos-fazer-fuahcontra-toda-forma.html. Acessado em: 30 mar. 2018.

HARAWAY, Donna. Saberes localizados: a questão da ciência para o feminismo e o privilégio da perspectiva parcial. Cadernos Pagu, Campinas, n. 5, 1995, p. 07-41.

HOOKS, bell. A teoria como prática libertadora. In: HOOKS, Bell (Org.). Ensinando a transgredir: a educação como prática libertadora. WMF Martins Fontes: São Paulo, 2013.

LORDE, Audre. There is no hierarchy of oppression. In: BYRD, Rudoph P.; COLE, Johnnetta B.; GUY-SHEFTALL, Beverly (Orgs.). I am your sister: collected and unpublished writings of Audre Lorde. New York: Oxford University Press, 2009, p. 219-220.

LOURO, Guacira Lopes. Gênero, sexualidade e educação: uma perspectiva pósestruturalista. Petrópolis: Vozes, 1997.

MALUF, Sônia Weidner; COSTA, Cláudia de Lima. Feminismo fora do centro: entrevista com Ella Shohat. Estudos Feministas, Florianópolis, v. 9, n. 2, 2001, p. 147-163. 
MORAGA, Cherríe; ANZALDÚA, Gloria (Orgs.). This bridge called my back: writings by radical women of color. 2. ed. New York: Kitchen Table, 1983.

MOVIMENTO DAS MULHERES TRABALHADORAS RURAIS DO NORDESTE. A estrada da sabedoria: sistematizando os caminhos para a formação de educadoras rurais do Nordeste (1994-2006). MMTR-NE: Caruaru-PE, 2006.

SANDOVAL, Chela: U.S. Third World Feminism: the theory and method of oppositional counsciousness in the postmodern world. Genders, Spring, no 23, 1991.

SANTANA, Paula. Estéticas e políticas feministas no cinema latino-americano contemporâneo: cartografias da imagem. Revista Fórum Identidades, Itabaiana-SE, v. 23, 2017, p. 69-85.

SILVA, Manu. Manu Silva: entrevista. Entrevistadora: Paula Santana. Serra TalhadaPE, mar. 2018. Entrevista concedida para elaboração do presente ensaio.

SPIVAK, Gayatri Chakravorty. Pode o subalterno falar? Belo Horizonte: Editora da UFMG, 2010.

WALLER, Alisha. What is feminist pedagogy and how can it be used in CSET education? In: 35th ASEE/IEEE FRONTIERS IN EDUCATION CONFERENCE, 2005, Indianapolis (USA). 